Thorax (1946), 1, 30-38.

\title{
HELIUM IN THE TREATMENT OF ASTHMA
}

\author{
BY \\ RICHARD DOLL \\ From the Medical Unit, St. Thomas's Hospital, London
}

\section{INTRODUCTION}

The substitution of helium for nitrogen in the inspired air has been advocated for two entirely different reasons. First, Sayers and Yant (1926) suggested that owing to the low solubility of helium its use in diving and other operations involving respiration under high pressure might reduce the incidence of caisson disease. Secondly, Barach (1934) suggested that the lesser mass of the helium molecule might make a helium-oxygen mixture easier to breathe than air in conditions of obstructed respiration and in asthma.

In support of this latter possibility Barach (1936) showed that in tracheotomized dogs, in which an obstruction had been inserted in the airway, the substitution of helium for nitrogen in the inspired air considerably reduced the negative intrapleural pressure on inspiration, for example, from -7.98 to -6.48 $\mathrm{cm}$. of water. At the same time what he defined as the 'pulmonary pressure,' that is, the pressure difference set up in the trachea on respiration, was also reduced, for example, from 3.56 to $2.4 \mathrm{~cm}$. of water. A similar experiment with men, in which the subjects breathed through a hole $\frac{1}{8}$ in. diameter, also showed a reduction of 25-50 per cent in the 'pulmonary pressure' with helium.

Barach concluded from these results that the use of helium-oxygen mixtures resulted in a saving of pulmonary effort, and that consequently there were grounds for thinking that relief might be obtained in cases of asthma, in which the increased pulmonary effort is an outstanding symptom.

Unfortunately asthma is a very variable condition, many cases having a large psychological element and others being complicated by a concomitant bronchitis. Consequently it is impossible to reach a final conclusion on the results of a small number of cases. However, in view of the considerable theoretical interest attached to the use of helium, it is worth while reviewing even a small experience.

\section{RESUltS}

In order to test Barach's hypothesis six cases of asthma admitted consecutively to St. Thomas's Hospital were treated by respiration of a mixture containing 80 per cent helium and 20 per cent oxygen, and their progress was followed. The gas was given through a B.L.B. oro-nasal mask. The type used was the original one described by Lovelace (1938), with a spring expiratory valve and three 
adjustable ports. The valve was unscrewed as far as possible so that any effect of expiring against a positive pressure (Barach and Swenson, 1939) should be minimal. The ports were kept closed and the rate of flow used was 8-11 litres a minute. This rate, which was more than enough to prevent the bag collapsing, was chosen to ensure that expired air was not collected in the bag; for Card, Forest Smith, Griffiths, McSwiney and Savage (1940) showed that though a maximal concentration of oxygen (approximately 90 per cent) could be obtained in the alveoli with 6-7 litres per min. there was, with this model, an appreciable collection of carbon dioxide in the bag (approximately 1 per cent) at rates less than 8.1 litres per minute.

To ensure that the patients' condition was steady they were first observed for $30-40$ minutes resting quietly in bed, screened-off from the rest of the ward. The mask was then placed in position and oxygen administered for a further period of 30-40 minutes. The oxygen was then switched off and administration of the helium mixture begun. The cylinders containing oxygen and the helium mixture were kept behind the head of the bed and were connected to the mask through a Y-piece. It was hoped that by this means the change from oxygen to the helium mixture might go unnoticed by the patient, so that any psychological effect could be eliminated. At the same time, any effect produced by the helium mixture could be compared with that produced by oxygen alone. After 30-60 minutes, in those patients whose clinical condition permitted it, oxygen was again switched on in place of the helium mixture, and finally all treatment was stopped.

A brief analysis of the history and clinical condition of the patients before treatment was started is given in Table $I$.

TABLE I

Showing the Clinical Details of the Patients Before Treatment

\begin{tabular}{|c|c|c|c|c|c|c|c|c|}
\hline Case & Sex & Age & $\begin{array}{l}\text { Length } \\
\text { of history }\end{array}$ & $\begin{array}{l}\text { Frequency of } \\
\text { attacks }\end{array}$ & $\begin{array}{c}\text { Usual duration } \\
\text { of attacks }\end{array}$ & $\begin{array}{c}\text { Duration } \\
\text { of } \\
\text { present } \\
\text { attack }\end{array}$ & $\begin{array}{c}\text { Severity } \\
\text { of } \\
\text { present } \\
\text { attack }\end{array}$ & $\begin{array}{c}\text { Reaction to } \\
\text { adrenaline } \\
\text { in present } \\
\text { attack }\end{array}$ \\
\hline 1 & M. & 61 & & $\begin{array}{l}\text { most nights } \\
\text { about } 2 \text { a.m. }\end{array}$ & & 2 hrs. & moderate & not given \\
\hline $\begin{array}{l}2 \\
3\end{array}$ & $\begin{array}{l}\text { M. } \\
\text { F. }\end{array}$ & $\begin{array}{l}36 \\
56\end{array}$ & $\begin{array}{l}20 \text { mnths. } \\
18 \text { yrs. }\end{array}$ & $\begin{array}{l}\text { one a month } \\
\text { most nights }\end{array}$ & $\begin{array}{l}4 \text { days } \\
\text { never quite free }\end{array}$ & $\begin{array}{l}3 \text { days } \\
\text { worse last } \\
2 \text { days }\end{array}$ & $\begin{array}{l}\text { severe } \\
\text { moderate }\end{array}$ & $\begin{array}{l}\text { poor } \\
\text { not given }\end{array}$ \\
\hline $\begin{array}{l}4 \\
5\end{array}$ & $\begin{array}{l}\text { M. } \\
\text { M. }\end{array}$ & $\begin{array}{l}25 \\
54\end{array}$ & $\begin{array}{l}4 \text { yrs. } \\
20 \text { yrs. }\end{array}$ & $\begin{array}{l}2 \text { or } 3 \text { a week } \\
\text { one a week }\end{array}$ & 4 hrs. & $\begin{array}{l}2 \text { hrs. } \\
2 \text { wks. }\end{array}$ & $\begin{array}{l}\text { moderate } \\
\text { moderate }\end{array}$ & $\begin{array}{l}\text { not given } \\
\text { nasal spray }\end{array}$ \\
\hline 6 & F. & 36 & 2 yrs. & most nights & $\frac{1}{2} \mathrm{hr}$. & $12 \mathrm{hrs}$. & mild & poor \\
\hline
\end{tabular}

The effect of treatment was observed by repeated measurements of the blood pressure, pulse and respiration rates, by the presence or absence of cyanosis, and by a clinical estimate of the patient's distress. Measurements of the chest expansion were made in the first two cases, but were abandoned, as they were difficult 
to make accurately and they did not alter appreciably when there was a marked change in the other measurements.

The observations made half an hour after the beginning of the control, oxygen, and helium periods are tabled below for comparison (Table II). This period was chosen because it generally took about half an hour for the patient's condition to become steady after changing the treatment. Observations made 10 minutes after the start of helium therapy are also included, because they seemed sufficiently constant to be significant.

TABLE II

Showing the EfFect of $100 \%$ Oxygen and a $80 \%$ Helium and $20 \%$ OXygen Mixture on the Blood Pressure, Pulse and Respiration Rates of 6 Asthmatics.

\begin{tabular}{|c|c|c|c|c|c|}
\hline Case & $\begin{array}{l}\frac{1}{2} \text { hr. after } \\
\text { start of } \\
\text { control period }\end{array}$ & $\begin{array}{l}\frac{1}{2} \mathrm{hr} \text {. after } \\
\text { start of } \\
\text { oxygen }\end{array}$ & $\begin{array}{l}10 \text { mins. after } \\
\text { start of } \\
\text { helium }\end{array}$ & $\begin{array}{l}\frac{1}{2} \text { hr. after } \\
\text { start of } \\
\text { helium }\end{array}$ & $\begin{array}{c}\text { After } \\
\text { Treatment }\end{array}$ \\
\hline $\begin{array}{l}1 \\
2 \\
3 \\
4 \\
5 \\
6\end{array}$ & $\begin{array}{l}155^{*} \\
125 \\
160 \\
125 \\
165 \\
125\end{array}$ & \multicolumn{2}{|c|}{\begin{tabular}{l|c}
\multicolumn{2}{c}{ Blood pressure $(\mathrm{mm} . \mathrm{Hg})$} \\
155 & 175 \\
125 & 175 \\
155 & 155 \\
125 & 125 \\
$200 \dagger$ & 225 \\
$125 \dagger$ & 125
\end{tabular}} & $\begin{array}{l}\frac{150}{165} \ddagger \\
\frac{120}{115} \ddagger\end{array}$ & $\begin{array}{r}170 \\
125 \\
220 \\
-\end{array}$ \\
\hline $\begin{array}{l}1 \\
2 \\
3 \\
4 \\
5 \\
6\end{array}$ & $\begin{array}{c}104^{*} \\
98 \\
96 \\
94 \\
102 \\
106\end{array}$ & $\begin{array}{l}\text { Puise } \\
102 \\
100 \\
90 \\
78 \\
108 \dagger \\
88 \dagger\end{array}$ & $\begin{array}{c}\text { te per min. } \\
106 \\
112 \\
104 \\
96 \\
118 \\
98\end{array}$ & $\begin{array}{l}\frac{90}{96} \ddagger \\
\frac{86}{98} \ddagger\end{array}$ & $\begin{array}{r}98 \\
100 \\
\overline{96} \\
106 \\
-\end{array}$ \\
\hline $\begin{array}{l}1 \\
2 \\
3 \\
4 \\
5 \\
6\end{array}$ & $\begin{array}{l}24^{*} \\
17 \\
24 \\
30 \\
21 \\
20\end{array}$ & $\begin{array}{l}\text { Respira } \\
20 \\
17 \\
16 \\
28 \\
23 \dagger \\
18 \dagger\end{array}$ & 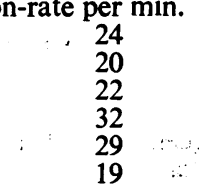 & $\begin{array}{l}\frac{17}{21} \ddagger \\
\frac{29}{19} \ddagger\end{array}$ & $\begin{array}{l}20 \\
16 \\
30 \\
28 \\
\end{array}$ \\
\hline
\end{tabular}

* Observed after 40 minutes.

$\dagger$ Observed after 20 minutes.

$\ddagger$ Not observed owing to patient's distress.

The full observations made on Cases 1,2 and 4 are shown graphically in Figs. 1,2 , and 3 .

In Case 2 (Fig. 2) the patient's distress became so severe on switching over to the helium mixture that the mask had to be removed and the treatment stopped. In Case 5 the result was almost identical, the helium having to be stopped after 13 minutes. In this patient the psychological factor was certainly of considerable importance, as was illustrated by his bad response to pure oxygen; unfortunately he appeared to have got the idea that he was being experimented on. 
In Cases 3 and 6 very little effect at all was noticed, save for a slight improvement with oxygen. These were the two mildest cases in the series.

In summary the observations showed-

(1) A slight general improvement with oxygen.

(2) A temporary aggravation of the distress in all cases on changing from oxygen to the helium mixture, which became maximal in from 10 to 15 minutes, and in two cases was so severe that the treatment had to be abandoned.

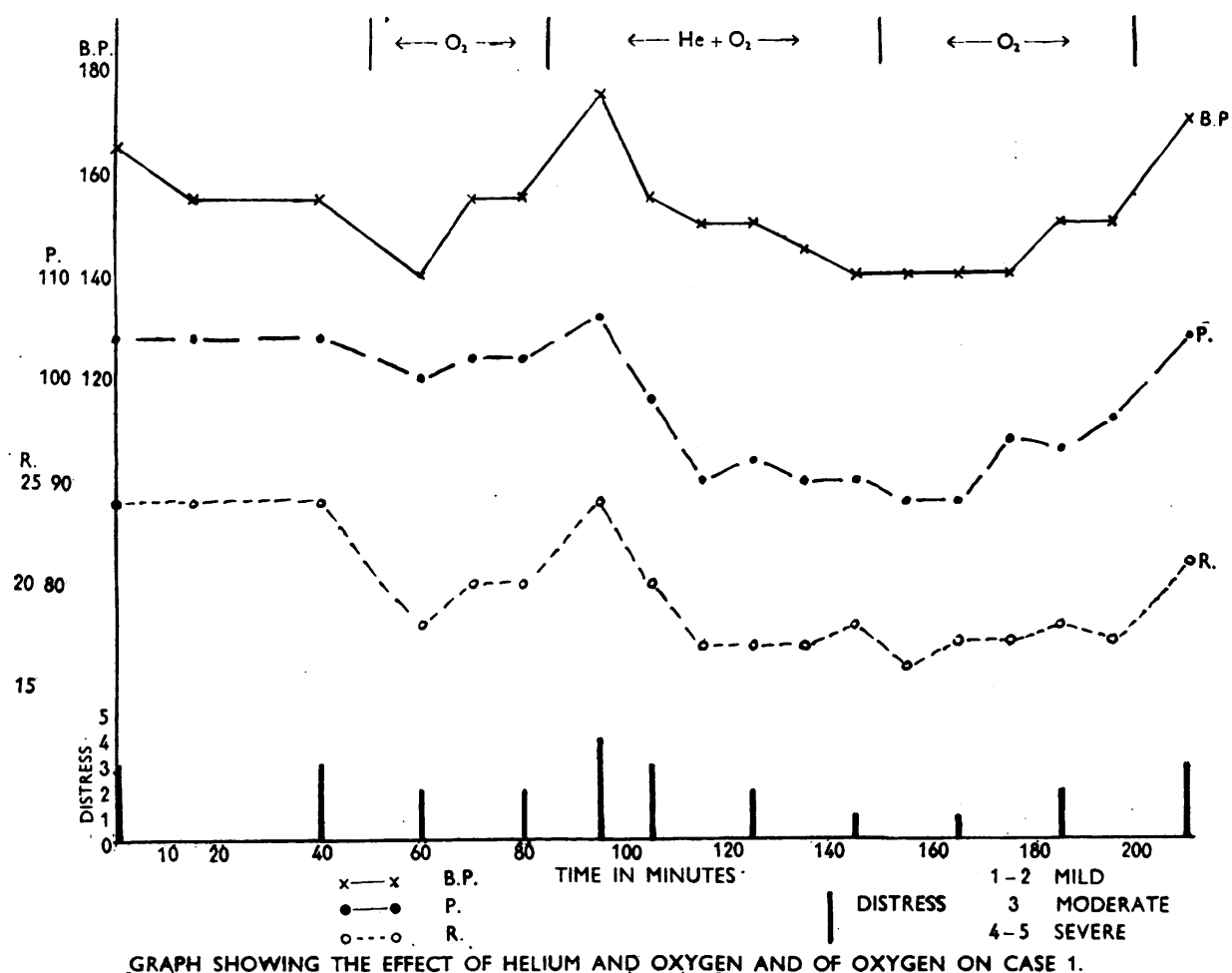

FIG. 1.

(3) Those patients who were able to tolerate the helium-oxygen mixture improved slowly after the initial period of exacerbation, until after half an hour there was a definite improvement.

(4) The degree of improvement with the helium, when it occurred, was not notably different from that obtained with 100 per cent oxygen.

(5) Cyanosis was present initially in Cases 1,2 and 3. It cleared with oxygen, but returned with the helium mixture.

(6) The patient's subjective distress was closely correlated with the objective changes in the blood pressure, pulse, and respiration rates. 
(7) Pulsus paradoxus, which was recognizable in all cases with the aid of the sphygmomanometer, was unaffected by treatment.

The finding of pulsus paradoxus in asthma was unexpected but was quite definite. The decrease in systolic pressure during inspiration varied from 10 to $40 \mathrm{~mm}$. of mercury in five cases, whilst in the other (Case 2) no pressure at all was recordable in late inspiration. In this case intermission of the pulse was also recognizable clinically. I have not been able to trace any other reference to the association of pulsus paradoxus with asthma, though it is well recognized to occur with laryngeal obstruction and other conditions resulting in severe dyspnoea.

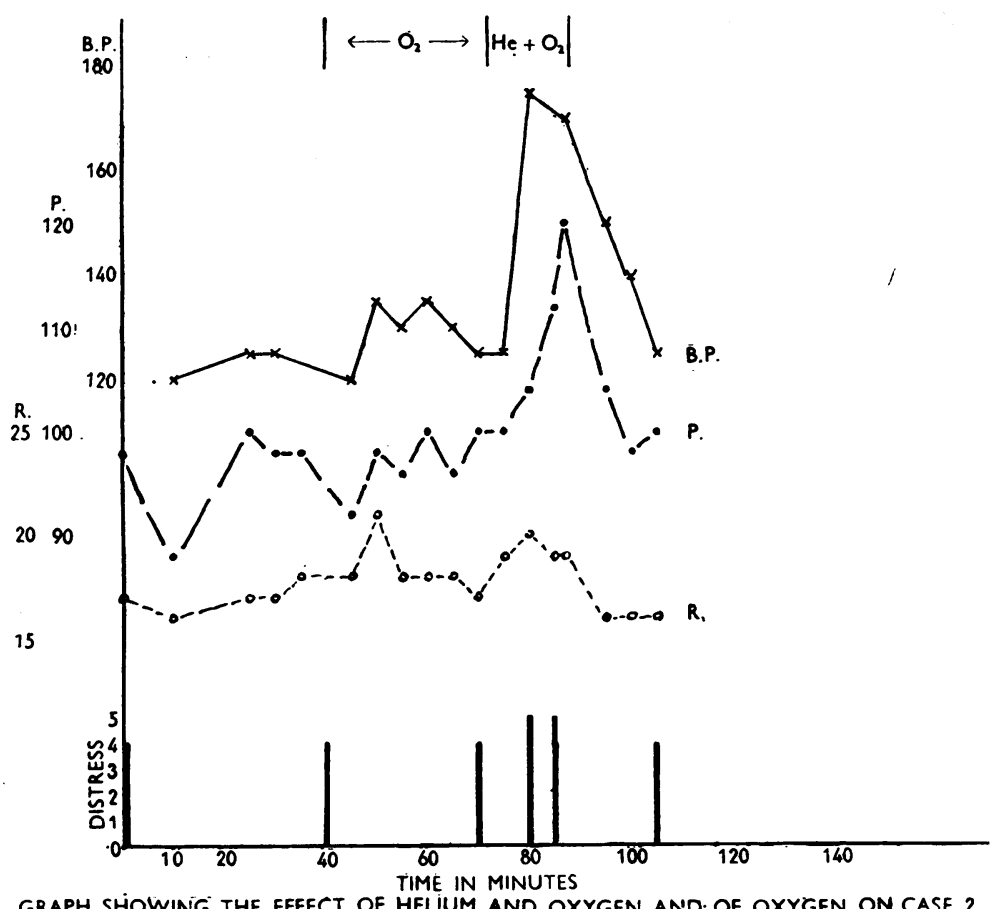

Fig. 2.

Whilst it is conceivable that an inspiratory reduction in systolic pressure could be the result of an increased negative intrapleural pressure dilating the lung capillaries and thus temporarily reducing the inflow to the left ventricle, it seems more likely that the effect was a local one produced by deformation of the subclavian artery as described by Falconer and McQueen (1915). According to them, such an effect is produced occasionally in normal people during forced inspiration, when it can be eliminated by bringing the shoulders forward.

\section{Discussion}

Barach's original assumption (1934) was that the light helium molecule would be easier to breathe than the heavier nitrogen molecule, because in moving a gas "work is in general proportional to the density" of the gas moved. He also 
believed that the smaller helium molecule would appreciably facilitate the flow of gases by increasing the rate of diffusion.

This thesis has been criticized by. Dean and Visscher (1941) on the grounds that it ignores the factor of gas viscosity. In his later works Barach has considered this aspect of the problem, and his present views are stated fully in his book on inhalational therapy (1945). His point is that his results (1936), which demonstrate decreased pulmonary effort on respiring helium, when the gases were

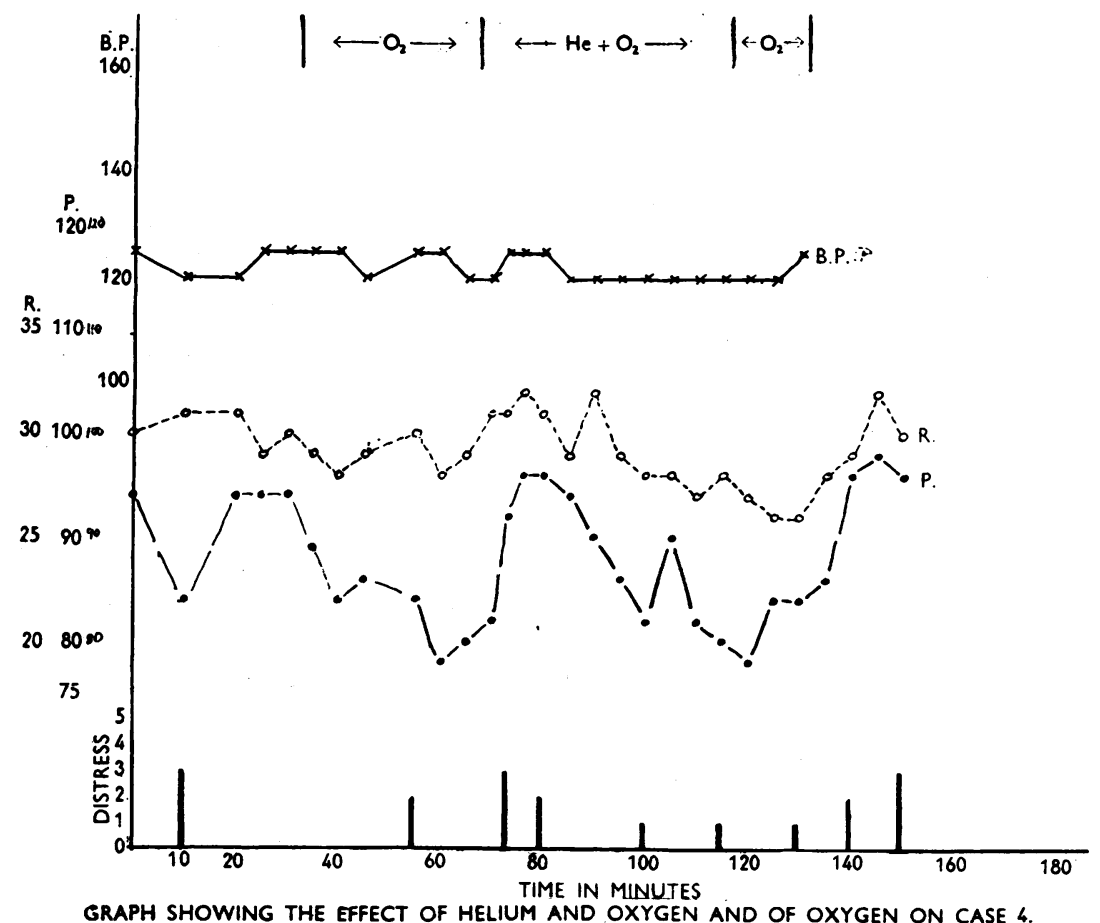

Fig. 3.

breathed through a partially obstructed orifice (see above), cannot be explained on the assumption that the work done in moving the respiratory gases is proportional to their viscosity-for the viscosity of helium is greater than that of air. He therefore concludes that the main gas movement must be by diffusion or effusion; in which case he states that the rate of flow obeys Graham's law for effusion, that is, it is inversely proportional to the square root of the molecular weight.

In fact the physical processes involved are very much more complicated. The rate of diffusion of a gas is, under normal conditions of temperature and pressure, slow in comparison with the rate of flow produced by pressure differences across an orifice. Were it not, there would be no need for respiratory movements, for oxygen would simply diffuse into the lungs and carbon dioxide diffuse out without 
any need for effort on the part of the animal at all. The only circumstance in which diffusion becomes the most important method of flow through an orifice is when the diameter of the orifice is small in comparison with the mean free path of the gas (Taylor, 1.931) ; as the mean free paths of helium and nitrogen (at N.T.P.) are of the order of 0.0003 and $0.0001 \mathrm{~mm}$. respectively, while the diameter of the smallest tubes in the lung is of the order of $0.1 \mathrm{~mm}$., it hardly seems likely that diffusion can play an important part in the flow of the respiratory gases. Moreover, when the diameter of the orifice is small in comparison with the mean free path of the gas, each constituent gas in a mixture behaves independently of the other gases, so that the substitution of helium for nitrogen would have no effect on the flow of oxygen or $\mathrm{CO}_{2}$.

On the other hand, conditions in the alveoli are different. Here there is no question of flow through an orifice, and the movement of gases from the centre of the alveolus to the lung membrane is largely by means of diffusion of one gas into another. The laws describing this process are very complicated (Taylor, 1931), but there is no doubt that in these circumstances the substitution of helium for nitrogen would increase the rate of diffusion of both oxygen and carbon dioxide, and it is possible that an improvement resulting from the use of helium might be due to this factor.

The alternative process of effusion mentioned by Barach is unlikely to play any part in the movement of gases in the respiratory passages. Effusion takes place when a gas passes through a tube whose diameter is small in comparison with the mean free path of the gas, as, for example, when a gas passes through a porous plate of gypsum, and once again the motion of one constituent in a mixture is independent of the others (Taylor, 1931).

Under the conditions which occur in the respiratory passages the methods of gas flow are either 'streamline' or 'turbulent.' These have been thoroughly examined by Dean and Visscher (1941). According to them, so long as gases move with streamline flow the advantage is all with air as compared with helium mixtures ; for then the pressure required to move a gas is proportional to the rate of flow of the gas and its viscosity, and the viscosity of an 80 per cent helium and 20 per cent oxygen mixture is 1.11 compared with 1.00 for air. However, as the rate of flow is increased a velocity is reached, the critical velocity, at which the flow becomes turbulent. When the flow is turbulent the pressure required to move a gas is proportional to the square of the velocity of the gas and to its density. Now an 80 per cent helium and 20 per cent oxygen mixture has a density of 0.33 against 1.00 for air, and so has a considerable advantage over air ; moreover, the mixture has the further advantage that its critical velocity is higher and that under conditions in which air is flowing turbulently a helium-oxygen mixture may still be flowing according to Poiseuille's law of streamline flow.

Dean and Visscher have shown that under normal conditions air probably flows in the respiratory tract in a streamline manner, and that the ideal method of producing turbulent flow in the respiratory tract is to introduce an obstruction into 
the largest passages. Experiments on dogs showed that in the absence of obstruction there was no reduction in respiratory effort on substituting helium for nitrogen, but that when an obstruction was placed in series with the trachea a considerable reduction was effected. On the other hand, after large doses of pilocarpine, which may be presumed to have constricted the peripheral bronchioles and simulated as nearly as possible the conditions of asthma, helium effected only a very slight reduction in the work required for ventilation. In fact, there was a 10 per cent reduction in the 'viscous ' work, but the 'elastic' work (required to distend the lungs), which had been markedly raised by the pilocarpine and formed the greater part of the work done, was unaltered.

Dean and Visscher concluded that helium and oxygen mixtures cause no reduction in respiratory effort during normal respiration, that they are unlikely to produce more than a minimal reduction, if any, in uncomplicated asthma, but that they may produce a considerable reduction in respiratory effort when the larger passages are obstructed. As a rough guide helium may be expected to be beneficial when respiration is very noisy, that is, when the air flow is turbulent.

Reports on the value of helium-oxygen mixtures in asthma leave the verdict non proven. Several papers claim that helium and oxygen is effective, particularly in cases of status asthmaticus and otherwise intractable asthma (Maytum, 1939; London, 1940 ; Barach and Cromwell, 1940). Barach (1935) reported four cases in detail in two of which relief was obtained immediately, and Maytum, Prickman and Boothby (1935) also reported three which "almost immediately improved both subjectively and objectively." It is interesting that in one of Barach's four cases (Case 3) there was the same difficulty in making the patient tolerate the mask that I found in two of my cases (Cases 2 and 5). According to his description " at first she struggled against the mask but after 15 min. of $80-82$ per cent helium she was relaxed and accepted treatment willingly." It is difficult to attribute this resistance entirely to the discomfort produced by the mask as oxygen had been previously well tolerated in my second case, and all my cases showed some objective signs of deterioration on changing from pure oxygen to the helium-oxygen mixture.

The difficulty in assessing these reports is that even the most severe asthma is largely conditioned by mental influences, and it is impossible to evaluate how far these may have played a part in the improvement. In no instance is any mention made whether the patient knew a fresh treatment was being given or not. However, in the majority of cases, treatment has had to be continued over a long period before lasting relief has been obtained. In his recent book Barach (1945) has reported 76 out of 84 cases of severe asthma were " decisively benefited" by helium-oxygen therapy, but treatment had to be continued for from one to five days and ancillary methods, namely, intravenous aminophyllin, were also employed. This need for a long period of treatment was commented on by Piness (1939), who stated that so far as he could see from the literature, patients treated 
with helium and oxygen did not obtain quicker relief than from other methods of treatment.

Whilst it is true that after ten years no outright condemnation of the method has been published, according to Visscher (1941) " in uncomplicated asthma it has not been conspicuously successful" ; my results lend support to this conclusion. Possibly the presence or absence of bronchitis in association with the asthma accounts for the different experiences.

\section{SUMMARY AND CONCLUSIONS}

(1) Six cases of mild to severe asthma were treated by respiration through a B.L.B. mask of an 80 per cent helium and 20 per cent oxygen mixture.

(2) Two patients were unable to tolerate the treatment. In the rest some improvement was noted comparable to that obtained from 100 per cent oxygen.

(3) Physical considerations indicate that helium is unlikely to be of great value in asthma, where the obstruction is in the smallest passages and where it is probable that at least part of the increased respiratory effort is due to changes in tissue elasticity.

(4) Where a respiratory obstruction exists in the larger passages, for example, laryngeal obstruction, there are good theoretical grounds, supported by experimental evidence, for expecting relief with helium.

\section{ACKNOWLEDGEMENTS}

My thanks are due to Sir Maurice Cassidy and Prof. O. L. V. S. de Wesselow for permission to treat their patients, and to Prof. B. A. McSwiney for his encouragement, to which the initiation of this work is due, and for his continued help and advice.

\section{REFERENCES}

Barach, A. L. (1934). Proc. Soc. exp. Biol., 32, 462.

Barach, A. L. (1935). Ann. intern. Med., 9, 739.

Barach, A. L. (1936). J. clin. Invest., 15, 47.

Barach, A. L. (1945). Principles and Practices of Inhalational Therapy, pp. 88 et seq.

Barach, A. L., and Cromwell, H. A. (1940). M. Clin. N. Amer., 24, 621.

Barach, A. L., and Swenson, P. C. (1939). Arch. intern. Med., 63, 946.

Card, W. I., Forest Smith, J., Griffiths, W. S., McSwiney, B. A., and Savage, B. (1940). Lancet, $1,398$.

Dean, R. B., and Visscher, M. B. (1941). Amer. J. Physiol., 134, 450.

Falconer, A. W., and McQueen (1915). Quart. J. Med., 8, 38.

London, M. (1940). Ohio St. med. J., 36, 945.

Lovelace, W. R. (1938). Proc. Mayo Clin., 13, 646.

Maytum, C. K. (1939). J. Allergy, 10, 264.

Maytum, C. K., Prickman, L. E., and Boothby, W. M. (1935). Proc. Mayo Clin., 10, 788.

Piness, G. (1939). J. Allergy, 10, 271.

Sayers, R. R., and Yant, W. P. (1926). Anesth. \& Analges., 5, 127.

Taylor, H. S. (1931). Physical Chemistry, 1, pp. 172 et seq.

Visscher, M. B. (1941). Proc. int. Assemb. post-grad. Ass. N. Amer., p. 320. 